\title{
PONDASI DERMAGA TYPE CAISSON UNTUK REHABILITASI PELABUHAN UJUNG PANDANG
}

\section{Irza Ahmad}

\begin{abstract}
Abstrak
Banyak sekali pelabuhan yang terdapat di Indonesia. Tentunya karena Indonesia terdiri dari pulau-pulau yang membutuhkan pelabuhan, baik pelabuhan besar maupun pelabuhan perintis.

Dari sekian banyak pelabuhan, terdapat satu pelabuhan yang memiliki pondasi yang direncanakan dengan pondasi Type Caisson yang merupakan satu-satunya di Indonesia, yaitu pelabuhan Ujung Pandang.

Pelabuhan ini merupakan pelabuhan yang direhabilitasi dengan memperluas dari pelabuhan yang telah ada.
\end{abstract}

Kata kunci : pelabuhan

\section{PENDAHULUAN}

Pada pembangunan proyek konstruksi dermaga untuk pembangunan pondasinya, orang lebih sering dan bahkan banyak menggunakan pondasi tiang pancang beton ataupun pondasi tiang pancang baja. Pemilihan tipe tiang pancang baja ini yang paling sering dipakai, berhubung dengan jenis lapisan tanah offshore yang ditemuinya batu karang atau pun sulitnya diperoleh bahan untuk beton. Sebaliknya bila lapisan batu karang dapat ditembus dan bahan beton mudah diperoleh, tentunya pondasi tiang pancang beton akan disenangi, terutama tiang pancang beton pre cast.

Pada saat sekarang ini akan dibangun pondasi untuk dermaga lebar yang tidak menggunakan tiang pancang, tapi pondasi tipe Caisson yang tentunya suatu hal yang baru untuk pelabuhan di Indonesia. Pemilihan pondasi ini tentunya telah sesuai, dimana Caisson dipakai untuk pondasi bangunan besar. Pemilihan tanah dasar pendukung untuk

Irza Ahmad, Ir.,MT.

Staf Pengajar Jurusan Teknik Sipil

Fakultas Teknik

Universitas Negeri Jakarta, 13220

Pondasi Dermaga Type Caisson Untuk Rehabilitasi Pelabuhan Ujung Pandang 
pondasi Caisson yang terbenam ke dalam tanah karena beratnya sendiri harus didasarkan pada penampang pondasi Caisson yang umumnya besar. Reaksi pada alas Caisson akan lebih besar dibandingkan dengan tahanan permukaan Caisson.

Berdasarkan pertimbangan di atas maka pemilihan pondasi Caisson untuk pelabuhan Ujung Pandang adalah tepat, mengingat pelabuhan tersebut adalah pelabuhan terbesar untuk pelabuhan Indonesia bagian timur.

Bagaimana merencanakan pondasi dermaga dengan tipe Caisson?

\section{METODA}

\section{Dasar Teori}

Penggolongan pondasi dari segi perencanaan, cara Caisson dibagi menjadi dua, yang satu dianggap sebagai pondasi langsung setelah menjalani penyempurnaan dan yang lain dianggap sebagai apa yang disebut dengan pondasi Caisson. Dalam hal ini umumnya dibuat perbandingan antara perbedaan kekakuan tubuh pondasi aatau dengan perkataan lain, perbandingan pergeseran pangkal tubuh Caisson akibat perbedaan sifat dinamis antar tubuh pondasi yang kaku dengan yang elastis, dan hal ini diapkai untuk menentukan apakah perencanaan tiang dianggap sebagai pondasi Caisson atau tidak.

Jadi jika suatu kolom dengan panjang $L(m)$ dan garis tengah $B(m)$, kekakuan lentur disebut $\mathrm{El}$, yang berada pada tanah serba sama (homogen) dengan koeffisien reaksi tanah $\mathrm{K}_{\mathrm{H}}\left(\mathrm{f} / \mathrm{m}^{3}\right)$, maka batas dimana pondasi dapat dianggap sebagai pondasi Caisson dapat dihitung dengan persamaan :

$$
L \sqrt[4]{\frac{K_{H} \bullet B}{4 E I}} \leq 1
$$

(Sumber : Nakazawa, Kazuto Cs, 1980)

\section{Stabilitas sewaktu tekanan ke atas}

Jika suatu caisson sedang mengapung ke dalam tempat di atasnya sendiri, maka stabilitas daya apung caisson harus dihitung untuk menjamin bahwa terbalikjungkir tidak 
akan terjadi. Untuk suatu caisson menjadi stabil, bila rumus (1.1) harus dipenuhi (lihat gambar.1.1)

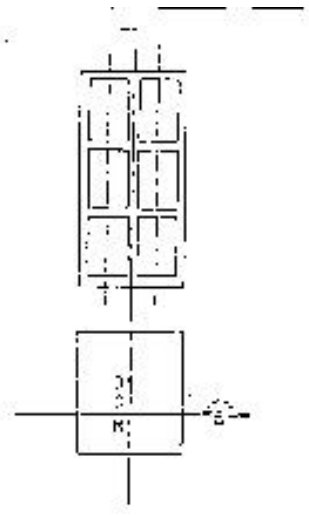

Gambar.1.1. Center of Bouyancy, Center of Gravity and Metacenter of Caisson (Sumber : Nakazawa, Kazuto Cs, 1980)

$$
\frac{I}{V}-\overline{C G}=\overline{G M}
$$

dimana V: Pergeseran tempat $\left(\mathrm{m}^{3}\right)$

I: Momen inersia bidang untuk sumbu panjang pada

$$
\text { permukaan bagan }\left(\mathrm{m}^{4}\right)
$$

C: Pusat tekanan ke atas

G: Pusat berat

M: Metacenter

Untuk menjamin keselamatan caisson sewaktu tekanan ke atas, maka itu diinginkan membuat GM menjadi $5 \%$ atau lebih dari bahan.

\section{Desain untuk gaya-gaya luar}
a. Beban sementara
b. Gaya luar selama pembuatan
c. Gaya luar selama penurunan dan tekanan ke atas

\section{Pelat dasar}

Luar pada pelat dasar $p_{2}$ harus yang diperoleh dengan pengurangan beban mati pelat dasar w dari tekanan hidrostatis pada pelat dasar $p_{w}$ (lihat Gambar.1.3) 


$$
\begin{aligned}
p_{2} & =p_{w}-w \\
& =w_{o} H_{o}-w
\end{aligned}
$$

(Sumber : Nakazawa, Kazuto Cs, 1980)

dimana $\mathrm{p}_{2}:$ Kerja tekanan hidrostatis pada pelat dasar $\left(\mathrm{t} t / \mathrm{m}^{2}\right)$

$\mathrm{p}_{w}:$ Kerja tekanan hidrostatis pada pelat dasar

kira-kira

w:Beban mati pelat dasar (termasuk berat caisson

sebagai imbangan, jika ada),dengan tekanan ke atas

tidak dikurangi $\left(\mathrm{t} / \mathrm{m} \mathrm{m}^{2}\right)$

$\mathrm{w}_{0}:$ Satuan berat air laut $=1,03 \mathrm{tf} / \mathrm{m}^{3}$

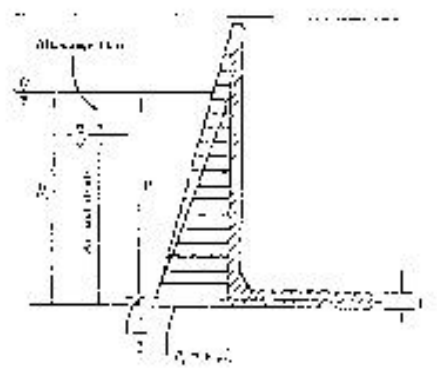

Gambar.1.2. Water Pressure Acting on Sidewall of Caisson (Sumber : Nakazawa, Kazuto Cs, 1980)

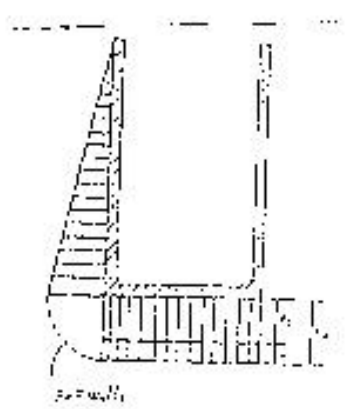

Gambar.1.3. External Force on Bottom Slan of Caisson

(Sumber : Nakazawa, Kazuto Cs, 1980)

\section{Gaya-gaya luar sewaktu penarikan (kapal)}


a. Tekanan hidrostatis, tekanan air dinamis dan tekanan ombak tidak dipertimbangkan.

b. Gaya tarik sewaktu penarikan.

Gaya tarik sewaktu penarikan suatu caisson harus dihitung menurut dengan persamaan (1.3) (lihat Gambar.1.x)

$$
T=\frac{w_{o}}{2 g} C_{o} v^{2} D
$$

(Sumber : Nakazawa, Kazuto Cs, 1980)

$$
\begin{aligned}
& \text { dimana } \mathrm{T} \text { : Gaya tarik (tf) } \\
& \text { g : Percepatan gravitasi }=9,8\left(\mathrm{~m} / \mathrm{s}^{2}\right) \\
& \mathrm{C}_{0} \text { : koefisien tarik } \\
& \text { V : kecepatan penarikan }(\mathrm{m} / \mathrm{s}) \\
& \text { A : bidang terbenam dinding saluran }\left(\mathrm{m}^{2}\right) \\
& A=a x(D+\delta) \\
& \text { D : bagan } \\
& \delta \text { : permukaan air di depan caisson (m) } \\
& \text { I : panjang caisson (m) } \\
& \text { a : lebar caisson (m) } \\
& \mathrm{w}_{0} \text { : berat satuan air laut }=1,03 \mathrm{tf} / \mathrm{m}^{3}
\end{aligned}
$$

5. Gaya luar sewaktu pemasangan

a. Tekanan hidrostatis pada dinding samping dan pelat dasar tidak dipertimbangkan sewaktu pemasangan.

b. Kepala tekanan hidrostatis antara kamar-kamar harus diterapkan pada dinding partisi sebagai gaya luar. (lihat Gambar.1.5)
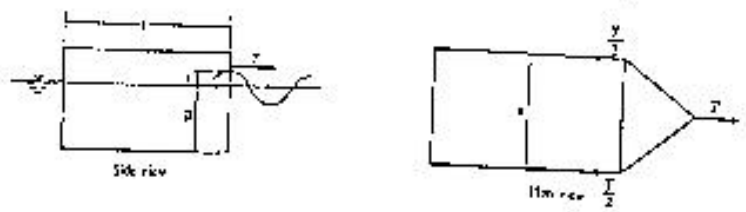

Gambar.1.4. Tractive Force during Towing (Sumber : Nakazawa, Kazuto Cs, 1980) 


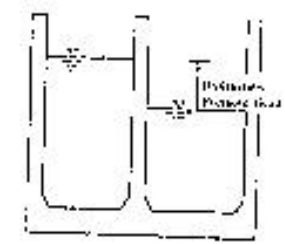

Gambar.1.5. Hydrostatic Head Between Chambers

(Sumber : Nakazawa, Kazuto Cs, 1980)

\section{Gaya luar sesudah pembangunan}

a. Dinding samping

1. Tekanan tanah urugan

2. Tekanan air di samping

3. Perhitungan tekanan samping

b. Pelat dasar

1. Kerja beban-beban desain pada pelat dasar dapat ditentukan oleh kaitannya pada pendistribusian beban.

2. Reaksi pada dasar permukaan caisson. Reaksi-reaksi dasar harus dihitung menurut rumus (1.4) dan (1.5) (lihat Gambar.1.6)
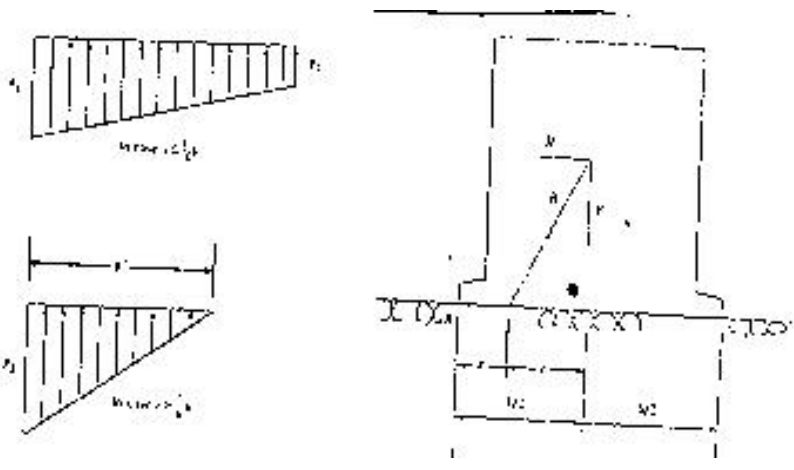

Gambar.1.6. Diagram of Bottom Reaction

(Sumber : Nakazawa, Kazuto Cs, 1980)

i) Jika $e \leq 1 / 6 b$ 


$$
\begin{aligned}
& p_{1}=\left(1+\frac{6 e}{6}\right) \frac{v}{b} \\
& p_{2}=\left(1-\frac{6 e}{6}\right) \frac{v}{b}
\end{aligned}
$$

(Sumber : Nakazawa, Kazuto Cs, 1980)

ii) Jika $e>1 / 6 b$

$$
\begin{aligned}
& p_{1}=\frac{2}{3} \frac{v}{\left(\frac{b}{2}-e\right)} \\
& b^{\prime}=3\left(\frac{b}{2}-e\right)
\end{aligned}
$$

(Sumber : Nakazawa, Kazuto Cs, 1980)

e diperoleh dari rumus (1.6)

$$
\begin{aligned}
& e=\frac{b}{2}-x \\
& x=\frac{M w-M n}{V}
\end{aligned}
$$

(Sumber : Nakazawa, Kazuto Cs, 1980)

$$
\begin{aligned}
\text { dimana } & \mathrm{P}_{1}: \text { reaksi pada tumir depan }\left(\mathrm{tt} / \mathrm{m}^{2}\right) \\
\mathrm{p}_{2} & : \text { reaksi pada tumir belakang }\left(\mathrm{tt} / \mathrm{m}^{2}\right) \\
\mathrm{V} & : \text { gaya resultante vertikal persatuan panjang }(\mathrm{tt} / \mathrm{m}) \\
\mathrm{H} & : \text { gaya resultante horizontal persatuan panjang }(\mathrm{t} f / \mathrm{m}) \\
\mathrm{e} & : \text { eksentrisitas resultante gaya } \mathrm{V} \text { dan } \mathrm{H} \\
\mathrm{b} & : \text { lebar dasar }(\mathrm{m}) \\
\mathrm{b}^{\prime} & : \text { lebar distribusi reaksi dasar, dalam hal e=1/6b }(\mathrm{m}) \\
\mathrm{M}_{\mathrm{V}} & : \text { Momen pada titik A oleh daya resultante vertikal }(\mathrm{tf} . \mathrm{m} / \mathrm{m}) \\
\mathrm{M}_{\mathrm{h}} & : \text { Momen pada titik A oleh daya resultante horizontal }(\mathrm{tf} . \mathrm{m} / \mathrm{m})
\end{aligned}
$$

c. Telapak pondasi (dasar landasan pondasi)

1. Beban bergerak yang bekerja pada landasan ditentukan dengan distribusi beban (lihat Gambar.1.7) 


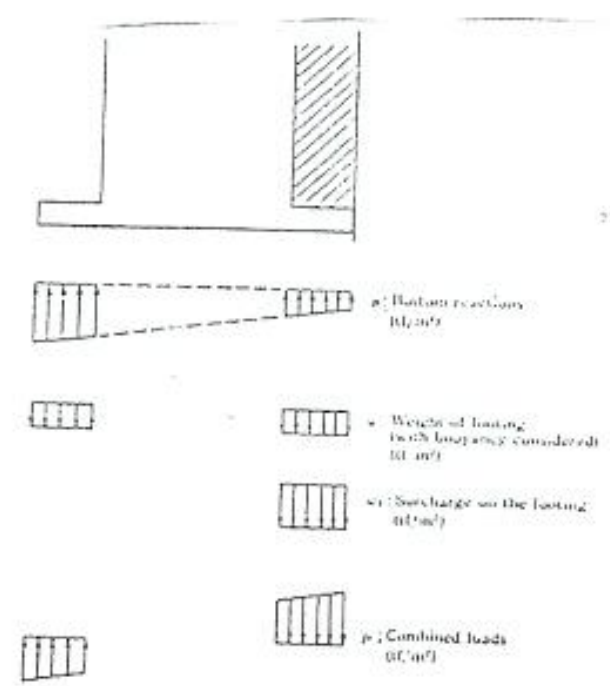

Gambar.1.7.Design Loads of Footing (Sumber : Nakazawa, Kazuto Cs, 1980)

2. Reaksi bawah yang bekerja pada landasan nilainya dihitung berdasarkan rumus (1.4) dan (1.5).

3. Berat landasan adalah yang dihitung di dalam air.

\section{d. Dinding partisi}

1. Beban desain untuk pemeriksaan di atas dapat ditentukan dengan kaitannya pada distribusi beban yang ditunjukkan dalam Gambar.1.8.

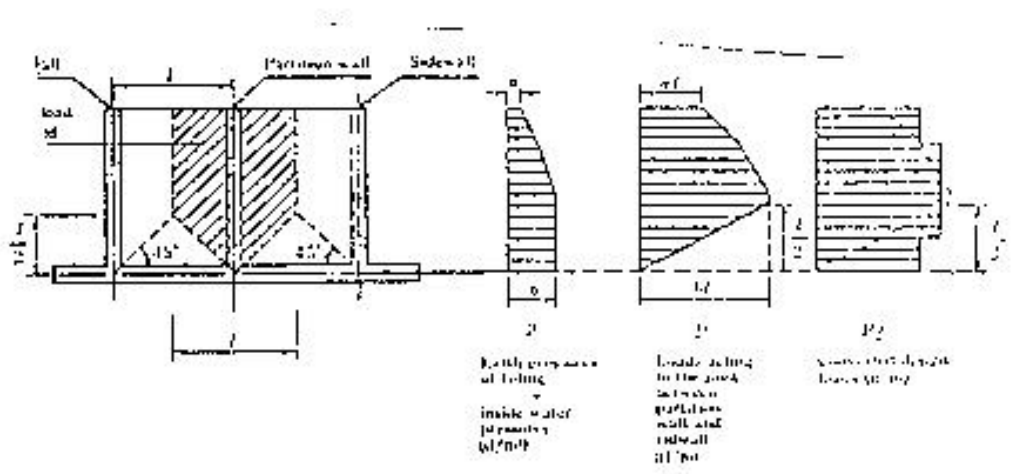

Gambar.1.8.Design Load to Examine Dislocation Failure of Partition Walls from Sidewalls 
(Sumber : Nakazawa, Kazuto Cs, 1980)

2. Distribusi beban yang ditunjukkan pada Gambar.1.9 dapat dipakai untuk menentukan beban-beban desain. Dan itu semua dianggap diperbuat pada hubungan antara dinding partisi dan pelat dasar.
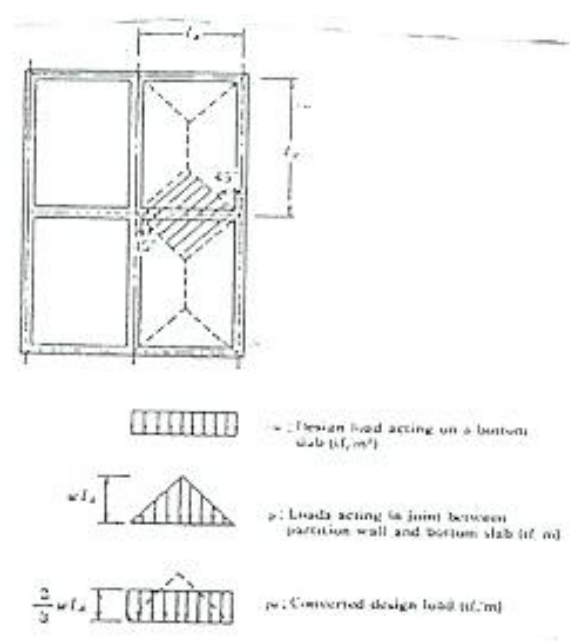
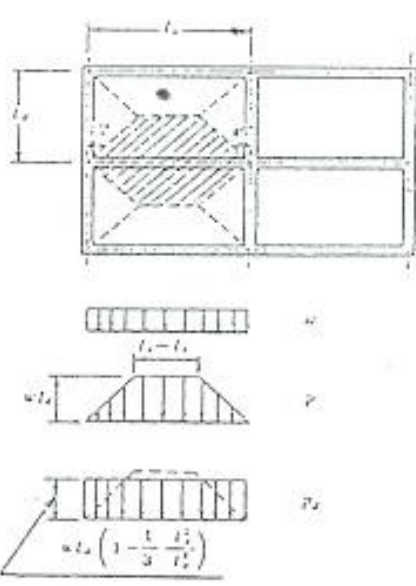

Gambar.1.9. Design Load for Examining Dislocation Failure of Partition Walls from Bottom Slabs (Sumber : Nakazawa, Kazuto Cs, 1980)

\section{HASIL DAN PEMBAHASAN}

\section{Aplikasi pada proyek rehabilitasi pelabuhan Ujung Pandang/Sulawesi Selatan}

1. Data

a. Data perencanaan

(1) Perencanaan dari ukuran kapal adalah dengan

(2) Beban yang diambil untuk dermaga

b. Dimensi dari dermaga

c. Kestabilan dari struktur pondasi caisson ditinjau dari 3 aspek 
(1) Sliding dengan safety factor : 1,2 untuk keadaan normal; 1,0 untuk gempa.

(2) Overturning (guling) dengan Safety factor : 1,2 untuk keadaan normail; 1,10 untuk gempa.

(3) Daya dukung pondasi dengan Safety factor : 2,5 untuk keadaan normal; 2,5 untuk keadaan normal.

d. Koefisien gempa

$$
\begin{aligned}
& \mathrm{Cd}=\mathrm{C} . \mathrm{I} . \mathrm{K} \\
& \begin{aligned}
\operatorname{dimana} \mathrm{C}= & 0,05 \text { (Zone IV) } \\
& \mathrm{I}=1,0 \\
& \mathrm{~K}=1,0
\end{aligned}
\end{aligned}
$$

e. Metode pembuatan caisson box (16 m panjang, $16 \mathrm{~m}$ lebar, 14,3 m tinggi) adalah sistem dry dock atau floating dock. Tapi dalam kasus ini yang dipakai adalah floating dock. Berat sebuah caisson box adalah 1600 ton, dan dicetak 4 buah caisson pada waktu yang sama. Untuk tinggi caisson 14,3 m dibutuhkan empat steps pekerjaan (3,5m tiap step).

Dermaga membutuhkan 44 caisson dan setiap launching adalah 4 caisson bersamaan.

f. Launching dari caisson

Pada saat launching, floating dock tenggelam untuk 4 buah caisson. Kedalaman caisson adalah 6,25 m. Bagaimanapun, jika jarak gandengan ke penempatan jauh, dianjurkan untuk meletakkan ballast pada caisson untuk stabilitas ekstra.

\section{g. Peralatan}

Tug boat dengan spesifikasi 450 PS

Flat ponton

Crame barge dengan grab

Sand barge

Diver boat 


\section{h. Penyelidikan tanah}

Tes yang dilakukan adalah konsolidasi, triaxial, unconfined compression untuk contoh soft cohesive soil.

SPT dan core untuk soft soil. (Data terlampir)

\section{Perhitungan struktur caisson}

a. Gaya dan beban pada caisson untuk keadaan normal.

Perhitungan gaya dan momen

\begin{tabular}{|l|c|c|c|c|}
\hline \multirow{2}{*}{ Beban } & \multicolumn{2}{|c|}{ Akibat beban vertikal } & \multicolumn{2}{c|}{ Akibat beban horizaontal } \\
\cline { 2 - 5 } & Gaya $(\mathrm{t} / \mathrm{m})$ & Momen $(\mathrm{tm} / \mathrm{m})$ & Gaya $(\mathrm{t} / \mathrm{m})$ & Momen (tm/m) \\
\hline 1. Struktur & 530,4 & 4,22 & - & - \\
2. Up lift & $-215,9$ & $-1,727$ & - & - \\
3. Tekanan tanah & 15,1 & 0,242 & 64,3 & 396 \\
$\quad$ dan air & 38,6 & 0,252 & & - \\
4. Berat crane & 368,2 & 2,987 & 64,3 & 396 \\
\hline \multicolumn{1}{|c|}{ Total } & & & & \\
\hline
\end{tabular}

Gaya dan beban pada caisson untuk keadaan gempa

\begin{tabular}{|c|c|c|c|c|}
\hline \multirow[t]{2}{*}{ Beban } & \multicolumn{2}{|c|}{ Akibat beban vertikal } & \multicolumn{2}{|c|}{ Akibat beban horizaontal } \\
\hline & Gaya (t/m) & Momen (tm/m) & Gaya (t/m) & Momen $(\mathrm{tm} / \mathrm{m})$ \\
\hline 5. Struktur & 530,4 & 4,22 & 26,5 & 211 \\
\hline 6. Up lift & $-215,9$ & $-1,727$ & - & - \\
\hline $\begin{array}{l}\text { 7. Tekanan tanah } \\
\text { dan air }\end{array}$ & 16,8 & 289 & 70,7 & 420 \\
\hline 8. Berat crane & 25,9 & 86 & 1,3 & 20 \\
\hline Total & 357,2 & 2,847 & 98,5 & 651 \\
\hline
\end{tabular}

b. Perhitungan sliding

Safety factor untuk sliding adalah 
$F s=W \times f / P$

dimana : Fs = Safety factor

$$
\begin{aligned}
& W=\text { beban dan gaya vertikal } \\
& P=\text { Gaya horizontal } \\
& f=\text { Faktor geseran antara caisson dengan batuan dasar }=0,6
\end{aligned}
$$

c. Perhitungan momen guling dengan safety faktor sebagai berikut : $\mathrm{Fs}=\mathrm{Mr} / \mathrm{Mo}=$

$\mathrm{Wx} / \mathrm{Px}$

dimana : Fs = Safety factor

$$
\begin{aligned}
& \mathrm{Mr}=\text { Momen tahanan }(\mathrm{tm} / \mathrm{m}) \\
& \mathrm{Mo}=\text { Momen guling }(\mathrm{tm} / \mathrm{m})
\end{aligned}
$$

d. Perhitungan daya dukung pondasi

Perhitungan daya dukung dengan anggapan distribusi beban dengan tinggi $3 \mathrm{~m}$ racle mound dan sudut geser $30^{\circ}$. Gaya reaksi pada permukaan Rock Mound.

$$
\begin{aligned}
& E=B / 2-x \\
& X=(M r-M o) / P \\
& \text { Jika }: e>B / 6 \\
& P_{1} r=(1+6 e / B) P / B \\
& P_{2} r=(1-6 e / B) P / B
\end{aligned}
$$

Jika : e $<B / 6$

$$
\begin{aligned}
& P_{1}=2 / 3 P /(B / 2-e) \\
B^{\prime}= & 3(B / 2)-e
\end{aligned}
$$

dimana : e = eksentrisitas dari gaya dan beban $(\mathrm{m})$

$$
\begin{gathered}
\text { B }=\text { lebar dasar pondasi }(\mathrm{m}) \\
\mathrm{B}^{\prime}=\underset{\text { lebar dasar pondasi sesudah distribusi }}{ } \\
\text { beban }(\mathrm{m}) \\
\mathrm{Mr}=\text { Momen resisten }(\mathrm{tm} / \mathrm{m}) \\
\mathrm{Mo}=\text { Momen awal }(\mathrm{tm} / \mathrm{m}) \\
\mathrm{P}_{1} \mathrm{r}, \mathrm{P}_{2} \mathrm{r}=\text { gaya pada Rocle }\left(\mathrm{t} / \mathrm{m}^{2}\right) \\
\mathrm{P}=\text { beban dan gaya vertikal total pada }
\end{gathered}
$$


Caisson $(\mathrm{t} / \mathrm{m})$

Gaya reaksi pada permukaan Replaced Sand

$$
P_{1} S=B \times P_{1} r / L+W r \times D
$$

dimana : $L=B+D \tan (30+\theta)+\tan (30-\theta)$

$$
\Theta=\tan ^{-1}(\Sigma \mathrm{H} / \Sigma \mathrm{W})
$$

Daya dukung yang diizinkan dengan Rumus Terzaghi :

$$
q_{a}=\left(W_{1} \times B \times N r+W_{2} \times D \times N q\right) / F+W_{2} \times D
$$

dimana : $q_{a}=$ daya dukung yang diizingkan $\left(t / \mathrm{m}^{2}\right)$

$$
\mathrm{B}=\text { lebar minimum pondasi }(\mathrm{m})
$$

$\mathrm{D}=$ kedalaman over burden di atas pondasi $(\mathrm{m})$

$W_{1}=$ berat unit tanah di bawah pondasi $\left(\mathrm{t} / \mathrm{m}^{3}\right)$

$\mathrm{W}_{2}=$ berat unit tanah di atas pondasi $\left(\mathrm{t} / \mathrm{m}^{3}\right)$

$$
F=\text { safety factor }=2,5
$$

$\mathrm{Nr}, \mathrm{Nq}=$ bearing capacity factor

$$
\begin{gathered}
\text { untuk } \varnothing=30^{\circ}-\mathrm{Nr}=7 \\
\mathrm{Nq}=8,5
\end{gathered}
$$

$$
\beta=\text { faktor bentuk pondasi, } 0,5 \text { untuk }
$$

pondasi menurun

e. Hasil perhitungan adalah seperti tabel di bawah :

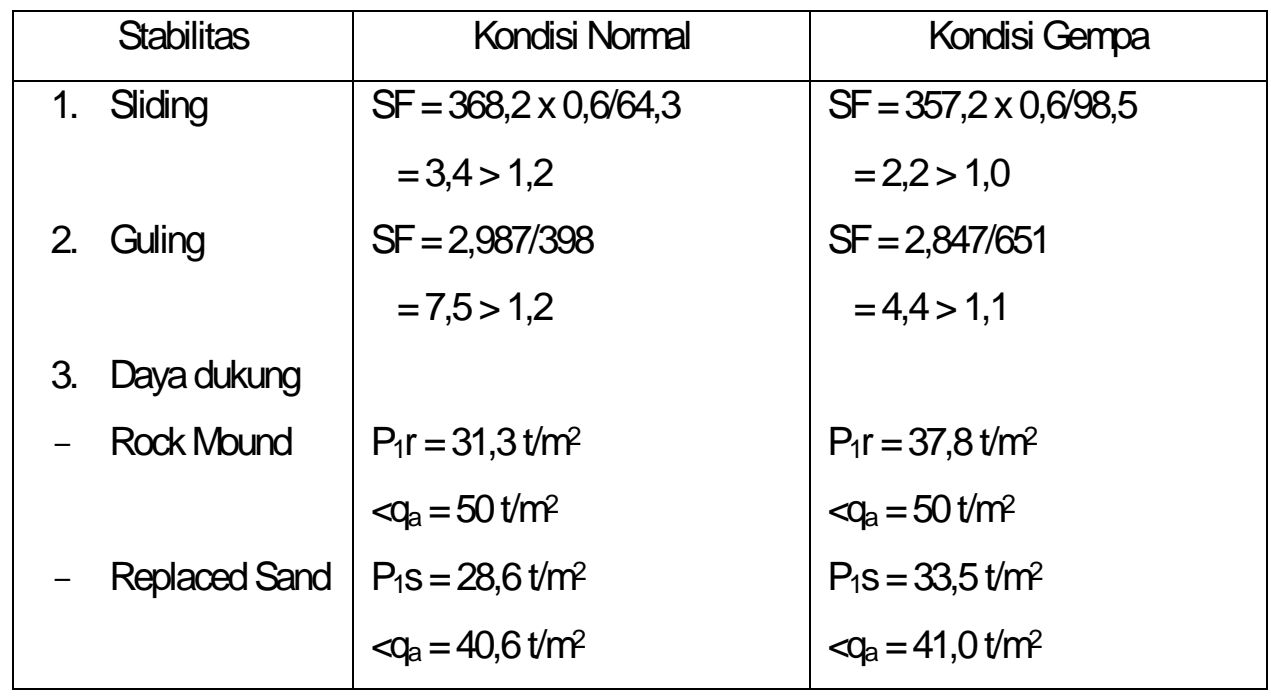




\section{KESIMPULAN}

a. Pembangunan pondasi untuk dermaga pada pelabuhan yang besar sebaiknya dipertimbangkan apalagi sebagai pelabuhan utaman

b. Pemilihan pondasi caisson pada pelabugan Ujung Pandang adalah tepat mengingat kondasi pelabuhan yang lama yang sudah padat dan rusak berat.

c. Dari hasil perhitungan stabilitas sendirinya pondasi caisson cukup besar dengan sendirinya terjamin keamanannya terhadap ketiga faktor yang ditinjau yaitu Sliding, Over Turning, dan Bearing Capacity Overturning.

\section{DAFTAR PUSTAKA}

Burcan of Port Harbour and Port Harbour Research, Institute Ministry of Transport, 1983 ; Technical Standard Port and Harbour facilities in Japan, Tokyo-Japan

Direktorat Jendral Perhubungan Laut 1983, Design Report, Jakarta.

Nakazawa, Kazuto Cs, 1980, Soil Mechanics and Foundation Engineering, diterjemahkan oleh Ir. L. Taulu dkk, dalam Mekanika Tanah dan Teknik Pondasi; P.T. Pradnya Paramita, Jakarta 